\title{
Diagnostic Value of non-contrast CT in Cerebrospinal Fluid Leakage after Endoscopic Transnasal Surgery for Sellar and Suprasellar Tumors
}

\section{Wei Gao}

Changxing People's Hospital, Changxing, Zhejiang Province

\section{Xiaoyu Wang}

Second Affiliated Hospital of Zhejiang University

\section{Sheng Zhang}

Zhejiang Provincial People's Hospital

\section{Yuanjian Fang}

Second Affiliated Hospital of Zhejiang University

Chenguang Li ( 2315084@zju.edu.cn)

Second Affiliated Hospital of Zhejiang University

\section{Research Article}

Keywords: cerebrospinal fluid leakage, endoscopic transnasal surgery, head CT, pneumocephalus, diagnosis

Posted Date: January 4th, 2021

DOl: https://doi.org/10.21203/rs.3.rs-132675/v1

License: (c) (i) This work is licensed under a Creative Commons Attribution 4.0 International License. Read Full License

Version of Record: A version of this preprint was published at Frontiers in Oncology on January 20th, 2022. See the published version at https://doi.org/10.3389/fonc.2021.735778. 


\section{Abstract \\ Background}

To study the relationship between pneumocephalus on non-contrast computed tomography (NCCT) and post-operative cerebrospinal fluid leakage ( $\mathrm{p}-\mathrm{CFL}$ ) after endoscopic transsphenoidal sellar and suprasellar tumors surgeries.

\section{Methods}

Patients who underwent endoscopic treatment for sellar or suprasellar tumors from January 2018 to March 2020 were consecutively collected and reviewed. The NCCT pneumocephalus (NP) was measured on the first day after operation and the first day after expansive sponge was extracted, respectively. $\mathrm{p}-\mathrm{CFL}$ was defined as the glucose rhinorrhea content $\geq 1.7 \mathrm{mmol} / \mathrm{L}$ in patients who had persistent nasal discharge of clear water-like fluid exacerbated by bending over or performing a Valsalva maneuver.

\section{Results}

Of 253 patients finally enrolled into this study, 32 patients (12.6\%) were identified as p-CFL. Compared with patients who had no $p-C F L$, patients with $p-C F L$ had a higher occurrence of intraoperative CFL, a longer operation duration time, a higher rate of the presence of pneumocephalus on the first-day NCCT after operation (referred to as the first-day NP), and a higher rate of NP volume change between two times NCCT measurements (referred to as the NP change) (all $P<0.05$ ). In multivariate regression analysis, the first-day NP was independently associated with the occurrence of p-CFL $(O R=6.176,95 \% \mathrm{Cl}=2.134-$ 17.871, $P=0.001)$. While adding the NP change into the regression model, the first-day NP was no longer independently associated with the occurrence of $p-C F L$, and the NP change $(O R=21.192,95 \% \mathrm{Cl}=6.292-$ $71.373, P<0.001)$ was independently associated with $\mathrm{p}-\mathrm{CFL}$. The ROCs comparison analysis showed that the NP change had a significantly better predicting value than the first-day NP (AUC: 0.988 vs $0.742, Z=$ 6.451, $P=0.001$ ).

\section{Conclusions}

NP is an effective imaging marker for predicting p-CFL after endoscopic sellar and suprasellar tumors operation, especially the NP change shows a better predicting value.

\section{Background}

Endoscopic transsphenoidal surgery is increasingly praised by neurosurgeons for the treatment of skull base lesions, but cerebrospinal fluid leakage (CFL) is a complication that is difficult to avoid completely, with an incidence as high as $11 \%$ now $^{1}$. The most common sites of surgical traumatic CFL are the 
ethmoid roof and the sphenoid sinus ${ }^{2}$. In one study, pituitary tumor resection made up nearly half of cases where tumor removal led to confirmed $\mathrm{CFL}^{3}$. CFL can lead to symptoms of low intracranial pressure, pneumocephalus and life-threatening intracranial infection, seriously affecting the prognosis of patients ${ }^{4,5}$. Although there are many ways to repair $\mathrm{CFL}$, such as lumbar cistern drainage, and multilayered fashion including fat tamponade, fascia lata, artificial dura, pediculate nasoseptal flap, balloon compression ${ }^{6-10}$, the leakage is still difficult to repair. Moreover, CFL after operation is difficult to detect and easily neglected by clinicians sometimes.

Therefore, early detection of CFL is quite important. Methods to date that are reported to diagnose CFL include urine the $\beta 2$-transferrin test, glucose rhinorrhea content analysis, High-Resolution Computed Tomography (HRCT), magnetic resonance imaging (MRI) and cisternography ${ }^{11-13}$. However, these methods are inconvenient, and have a certain probability of misdiagnosis. Pneumocephalus is a common clinical manifestation of CFL. In the case of low intracranial pressure, air can enter the brain from the leakage, resulting in pneumocephalus ${ }^{14,15}$. Non-contrast CT (NCCT) can show pneumocephalus clearly. Therefore, the presence of CFL can be indicated by pneumocephalus detected by NCCT after transsphenoidal surgery. At present, there is no study on the relationship between pneumocephalus on NCCT and CFL after transnasal surgery, therefore, the diagnostic value of post-operative NCCT for CFL is uncertain.

In this study, we analyzed the surgical cases of endoscopic transsphenoidal sellar and suprasellar tumors, focusing on the relationship between the occurrence and its volume change of NCCT pneumocephalus (NP) and CFL, in order to explore a new method of diagnosis of CFL.

\section{Methods}

\section{Ethics statement}

Each subject or an appropriate family member had given written informed consent prior to the study, and the protocols had been approved by the local ethics committee. All clinical investigation has been conducted according to the principles expressed in the Declaration of Helsinki.

\section{Study subjects}

The retrospective study included consecutively collected patients who underwent endoscopic treatment for sellar or suprasellar tumors from January 2018 to March 2020. Patients' demographics, medical history, pathological findings, and repair outcome were recorded. Pre- and post-operative imaging, operative reports, medical records, and operative videos were reviewed. We excluded (i) post-operative pathology was not tumor; (ii) incomplete imaging and clinical data from admission to discharge.

\section{Operation procedure}


Endoscopic resection of sellar or suprasellar tumors was performed routinely. Most operations were performed through the right single nostril. If sellar septum injury or CFL was noticed during operation, repair of CFL was performed. Our repair methods included lumbar cistern drainage, artificial dura repair, balloon compression, and autologous tissue like fat tamponade, fascia lata, pediculate nasoseptal flap (Fig. 1). Depending on the intraoperative conditions, the surgeon might choose some or all of these methods to reconstruct skull base. Regardless of the occurrence of CFL during surgery, we routinely filled the nasal cavity with an expansive sponge. expansive sponge was extracted on the third day after operation. The first head NCCT scan was performed on the first day after surgery, and the second CT scan was performed on the first day after extraction of expansive sponge.

Calculation of NP volume

The presence and the volume of NCCT pneumocephalus (NP) was measured on the first day after operation and the first day after expansive sponge was extracted, respectively. NP change was defined as the volume change between the first day after operation and 24 hours after expansive sponge was extracted, and it was further divided into four categories: no NP, decreased NP, unchanged and increased NP. The measurement method of pneumocephalus volume is shown in Fig. 2.

\section{Postoperative Diagnosis of Cerebrospinal Fluid Leakage (CFL)}

After the removal of the expansive sponge, CFL was highly suspected if the patient had persistent nasal discharge of clear water-like fluid exacerbated by bending over or performing a Valsalva maneuver. Rhinorrhea was collected, and the glucose rhinorrhea content $\geq 1.7 \mathrm{mmol} / \mathrm{L}$ was used to diagnose postoperative CFL ( $p-C F L)^{4}$. Patients were identified as non-p-CFL if the glucose rhinorrhea content < $1.7 \mathrm{mmol} / \mathrm{L}$ in glucose test of nasal leakage, or there was no nasal discharge after expansive sponge was extracted, even during Valsalva maneuver.

\section{Statistical analysis}

All numeric variables were expressed as mean \pm SD and median (interquartile range). Categorical variables were presented as frequency (percentage). Fisher exact test was used to compare dichotomous variables between groups, while Mann-Whitney $U$ test was used for ordered categorical variables, independent samples 2-tailed $t$ test or Mann-Whitney $U$ test was used for continuous variables, depending on the normality of the distribution. Variables identified by univariate analysis $(P<0.05)$ were included in binary logistic regression model. Adjusted odds ratios (OR) with $95 \%$ confidence intervals (Cl) were calculated and $P<0.05$ was considered significant. Receiver operative curve (ROC) analysis was performed to test the predictive power of independent variables for the dependent variable, through the calculation of areas under the ROC curve (AUC), sensitivity and specificity. All analyses were performed blinded to the participant identifying information. Statistical analysis was performed using SPSS 19 (SPSS Inc., Chicago, IL, USA). ROC curve comparison analyses were conducted by Medcalc statistical software version 15 (Medcalc Software, Mariakerke, Belgium). 


\section{Results}

\section{Characteristics of the Patients}

A total of 271 patients were reviewed, and we identified 253 patients who met the study criteria after excluding 18 patients for $\mathrm{i}$ ) post-operative pathology was not tumor $(n=12)$, and ii) incomplete imaging and clinical data from admission to discharge $(n=6)$. Of 253 patients, $49.6 \%$ were female, and the median patient age was 50y (IQR:40-60y).

Of all the 253 patients, 40 (15.8\%) showed the first-day NP after operation. After the extraction of expansive sponge, 46 patients $(18.2 \%)$ showed the NP change, and $32(12.6 \%)$ were finally identified as p$\mathrm{CFL}$. The median test time for $\mathrm{p}-\mathrm{CFL}$ was $2 \mathrm{~d}$ (IQR:1-5d) after the removal of the expansive sponge, and $62.5 \%$ of $p$-CFL patients were tested beyond $2 \mathrm{~d}$ after the removal of the expansive sponge.

Compared with non-p-CFL group, $\mathrm{p}-\mathrm{CFL}$ group showed a significantly longer duration of hospitalization, a higher rate of post-operative infection $\left(62.5 \%\right.$ vs $\left.11.8 \%, \chi^{2}=48.090, P<0.001\right)$ (Table I). Ten patients received the repairment operation once or more, but still 2 of them were dead because of severe intracranial infection during hospitalization.

\section{Factors influencing the occurrence of p-CFL}

Compared with patients with no p-CFL, patients with p-CFL had a higher rate of intraoperative CFL, a higher use of free fat interositional graft, lumbar cistern drainage, balloon compression, artificial dura mater implantation, and a longer duration time of operation (all $P<0.05$ ). After resecting tumors, patients with p-CFL showed a higher rate of the first-day NP and the NP change during hospitalization, a higher occurrence of high fever and infection, and a longer duration of hospitalization (all $P<0.05)$ (Table I).

In patients with the NP change $(n=46)$, ten patients of decreased-NP subgroup who initially showed the first-day NP but were found of no NP at the follow-up NCCT were finally proved of no p-CFL. Sixteen patients who showed increased NP between two times NCCT measurements were all finally proved as pCFL, including six patients showed no NP at the first-day NCCT but were found of NP at the follow-up NCCT after the extraction of expansive sponge (Fig. 3).

In multivariable regression analysis, when adding the variable of the first-day NP into the regression model, the first-day NP $(\mathrm{OR}=6.176,95 \% \mathrm{Cl}=2.134-17.871, P=0.001)$ and operative duration time $(\mathrm{OR}=$ $1.027,95 \% \mathrm{Cl}=1.017-1.036, P<0.001)$ were independently associated with the occurrence of $p-C F L$, after adjusting for trans-single nostril, pathology types and tumor size (Model 1, Table II).

When adding the NP change into the regression model, the first-day NP was no longer independently associated with the occurrence of $\mathrm{p}-\mathrm{CFL}$. However, the NP change $(\mathrm{OR}=21.192,95 \% \mathrm{Cl}=6.292-71.373, P$ $<0.001)$ and operative duration time $(\mathrm{OR}=1.019,95 \% \mathrm{Cl}=1.003-1.034, P=0.018)$ were factors independently associated with p-CFL (Model 2, Table II). Compared with patients with increased NP, patients with no NP had significantly a lower risk for the occurrence of $\mathrm{p}-\mathrm{CFL}(\mathrm{OR}=0.004,95 \% \mathrm{Cl}=0.001-$ 
$0.037, P<0.001)$. While compared with patients with no NP, patients with unchanged $(\mathrm{OR}=12.745,95 \% \mathrm{Cl}$ $=3.170-40.254, P<0.001)$ and increased NP $(\mathrm{OR}=22.497,95 \% \mathrm{Cl}=6.250-62.421, P<0.001)$ had significantly higher risk of $\mathrm{p}$-CFL.

The comparison of predictive power for $\mathrm{p}$-CFL between post-operative NCCT pneumocephalus and volume change of NP

ROC analysis showed that, the AUC of the first-day NP for predicting p-CFL was $0.742(95 \% \mathrm{Cl}=0.529-$ $0.755, P=009)$, with the sensitivity of $68.6 \%$ and the specificity of $87.8 \%$. The AUC of the NP change for predicting p-CFL was $0.988(95 \% \mathrm{Cl}=0.977-0.998, P<0.001)$, with the sensitivity of $100 \%$ and the specificity of $93.7 \%$. The ROCs comparison of these two parameters showed that the NP change had a significantly better predicting value than the first-day NP $(Z=6.451, P=0.001)$.

\section{Discussion}

Diagnosis and management of $\mathrm{p}-\mathrm{CFL}$ can sometimes be challenging, even for the most experienced neurosurgeons ${ }^{13}$. The presentation of clear rhinorrhea and/or headache is common in many conditions. Those that should be specifically considered as CFL are allergic rhinitis, common cold, vasomotor rhinitis, spontaneous intracranial hypotension, subarachnoid hemorrhage, and meningitis ${ }^{16,17}$. CFL could also pose a serious hazard, and it is associated with delayed wound healing, meningitis, epidural infections, and pneumocephalus. These complications often lead to prolonged hospitalization, reoperation, and increased health care costs ${ }^{18-21}$. The most serious potential complication of CFL is meningitis ${ }^{22}$. Two patients of our study died from Klebsiella pneumoniae infection. Thus, it is vital to find an early evidence to diagnose CFL. In this study, we found that both the first-day postoperative NCCT pneumocephalus (NP) and the volume change of NP (the NP change) could predict p-CFL, and the latter has a higher predictive value. Compared with no NP patients, patients with no change and increased NP had a higher risk of having $\mathrm{p}-\mathrm{CFL}$, and $100 \%$ of increased NP patient were proved of $\mathrm{p}-\mathrm{CFL}$.

The possible pathophysiology for the correlation between the presence of NP and p-CFL can be explained by two theories: the inverted bottle mechanism and the ball-valve mechanism ${ }^{15}$. In the inverted bottle mechanism, it is postulated that as CSF flows out of the subarachnoid space through a dural-arachnoid tear, negative pressure is created within the subarachnoid space. The negative pressure prevents the leakage of more CSF, until air enters to take its place and equilibrates the pressure differential. In the second theory, the ball-valve mechanism hypothesizes that air enters through a fracture next to an aircontaining space ${ }^{15}$. A vacuum drainage system predisposes a patient to a pneumocephalus in the presence of $\mathrm{CFL}^{15,23,24}$.

We found that the NP change after the extraction of expansive sponge can better predict p-CFL than the first-day NP. Head NCCT examination was performed on the first day after operation routinely. At that time the patient's bilateral nasal cavity was filled with expansive sponge and was in a continuous lying state. Even if there was cerebrospinal fluid leakage, cerebrospinal fluid was not easy to flow out of the nasal 
cavity. Also it was difficult for air to enter the brain. Therefore, if CFL is slight during and after operation, pneumocephalus is not easy to appear in early postoperative CT. When the patients underwent off-bed training after extraction for 1 day, the second CT scan was performed. At this time, if CFL existed, CSF would be more likely to flow out than before. The reduced intracranial pressure makes air more likely to enter the brain and causes pneumocephalus. Therefore, detecting the changes of NP volume can more effectively predict $\mathrm{p}-\mathrm{CFL}$ than observing the first NP. However, most of the patients discharged within 5 days after operation have made it difficult for us to do further CT dynamic observation.

In patients with the first-day NP after tumor resection, the occurrence of p-CFL was lower in patients with reduced NP volume comparing with those with increased or invariant NP volume. The probable cause is that pneumocephalus was gradually absorbed after the CFL was cured. CFL during operation and the loss of a large amount of CSF leading to pneumocephalus at first. However, after the leakage was properly repaired by skull base reconstruction, the postoperative pneumocephalus was gradually absorbed. In contrast, invariant and increase of CT pneumocephalus suggested a high incidence of CFL. If CFL is completely solved, pneumocephalus will be gradually absorbed, and CT re-examination at an interval of 3 days is enough to observe the reduction of pneumocephalus. If there is no change or increase of pneumocephalus volume after operation, it indicates that intracranial pressure continues to decrease and leakage still exists, so the incidence of p-CFL increases.

In this study, p-CFL happened in 2 patients who had no pneumocephalus on the first day after the operation. According to the dynamic evaluation, pneumocephalus was found in the head CT on the fourth day after the operation, suggesting that the dynamic review of head NCCT is of significance to the evaluation of CFL. In one case, although there was an increase in pneumocephalus volume after operation, there was no cerebrospinal fluid leakage, which may be related to the excessive drainage of cerebrospinal fluid caused by lumbar cistern drainage.

Our study is limited by the relatively small sample size, and further studies with larger sample size will be needed to confirm our results. An additional limitation is our retrospective and single-center methodology. Meanwhile, our observation time is short and limited to during hospitalization, requiring a longer followup.

\section{Conclusion}

In this study, we found that the NP change is a more convenient and effective imaging marker than the occurrence of the first-day NP for predicting p-CFL after endoscopic sellar and suprasellar tumors tumor operation. Using dynamic NCCT observation, attention should be paid to the risk of p-CFL in patients with no change and increased NP.

\section{Abbreviations}


NCCT: non-contrast computed tomography; NP:NCCT pneumocephalus; p-CFL:post-operational cerebrospinal fluid leakage; HRCT:High-Resolution Computed Tomography; MRI:magnetic resonance imaging.

\section{Declarations}

\section{Ethics approval and consent to participate}

We confirm that all methods were carried out in accordance with relevant guidelines and regulations and all experimental protocols were approved by the ethics committee of Second Affiliated Hospital of Zhejiang University.

\section{Consent for publication}

Written informed consent was obtained from the patient for the publication of this article.

\section{Availability of data and materials}

All data generated or analysed during this study are included in this published article [and its information files].

\section{Competing interests}

There is no conflict of interest in all co-authors.

\section{Funding}

This work was supported by the National Natural Science Foundation of China (grant number 81702462 , 81801162).

\section{Authors' contributions}

Wei Gao and Xiaoyu Wang: drafted the manuscript. Yuanjian Fang: acquisition of data. Sheng Zhang analysis or interpretation of data. Chenguang Li: study concept and design.

\section{Acknowledgements}

I would like to show my deepest gratitude to Dr. Chenguang Li who has provided me with valuable guidance.

\section{References}

1. Ivan ME, lorgulescu JB, El-Sayed I, McDermott MW, Parsa AT, Pletcher SD, et al. Risk factors for postoperative cerebrospinal fluid leak and meningitis after expanded endoscopic endonasal surgery. J Clin Neurosci. 2015 Jan;22(1):48-54. doi: 10.1016/j.jocn.2014.08.009. 
2. Psaltis AJ, Schlosser RJ, Banks CA, Yawn J, Soler ZM. A systematic review of the endoscopic repair of cerebrospinal fluid leaks. Otolaryngol Head Neck Surg. 2012 Aug;147(2):196-203. doi:10.1177/0194599812451090.

3. Banks CA, Palmer JN, Chiu AG, O'Malley BW Jr, Woodworth BA, Kennedy DW. Endoscopic closure of CSF rhinorrhea: 193 cases over 21 years. 2009 Jun;140(6):826-33. doi:10.1016/j.otohns.2008.12.060.

4. Li M, Mao S, Tang R, Lin H, Li D, Ye H, et al. Delayed Diagnosis and Treatment of Cerebrospinal Fluid Leakage in Current Practice. J Craniofac Surg. 2019 Sep;30(6):1657-1661. doi:10.1097/SCS.0000000000005402.

5. Majhi S, Sharma A. Outcome of Endoscopic Cerebrospinal Fluid Rhinorrhoea Repair: An Institutional Study. Indian J Otolaryngol Head Neck Surg. 2019 Mar;71(1):76-80. doi: 10.1007/s12070-018-14852.6 .

6. Illing E, Chaaban MR, Riley KO, Woodworth BA. Porcine small intestine submucosal graft for endoscopic skull base reconstruction. Int ForumAllergy Rhinol. 2013 Nov;3(11):928-32. doi: 10.1002/alr.21206.

7. Ismail AS, Costantino PD, Sen C. Transnasal Transsphenoidal Endoscopic Repair of CSF Leakage Using Multilayer Acellular Dermis. Skull Base. 2007 Mar;17(2):125-32. doi: 10.1055/s-2007-970556.

8. McCormack B, Cooper PR, Persky M, Rothstein S. Extracranial repair of cerebrospinal fluid fistulas: technique and results in 37 patients. Neurosurgery. 27(3):412-7,1990.

9. Saafan ME, Albirmawy OA, Tomoum MO. Sandwich grafting technique for endoscopic endonasal repair of cerebrospinal fluid rhinorrhoea. EurArch Otorhinolaryngol. 2014 May;271(5):1073-9. doi:10.1007/s00405-013-2674-y.

10. Sinha P, Desai SC, Ha DH, Chicoine MR, Haughey BH. Extracranial radial forearm free flap closure of refractory cerebrospinal fluid leaks: a novel hybrid transantral-endoscopic approach. Neurosurgery. 2012 Dec;71(2Suppl Operative):ons219-25; discussion ons225-6. doi:10.1227/NEU.0b013e3182684ac8.

11. Shelesko EV, Kravchuk AD, Kapitanov DN, Chernikova NA, Zinkevich DN. Sovremennyı̆ podkhod k diagnostike nazal'nol likvorei [A modern approach to the diagnosis of nasal liquorrhea]. Zh Vopr Neirokhir Im NN Burdenko. 2018;82(3):103-111. Russian. doi:10.17116/neiro2018823103.

12. Zapalac JS, Marple BF, Schwade ND. Skull base cerebrospinal fluid fistulas: a comprehensive diagnostic algorithm. Otolaryngol Head Neck Surg. 2002 Jun;126(6):669-76. doi: 10.1067/mhn.2002.125755.

13. Meco C, Oberascher G. Comprehensive algorithm for skull base dural lesion and cerebrospinal fluid fistula diagnosis. Laryngoscope. 2004Jun;114(6):991-9. doi: 10.1097/00005537-200406000-00007.

14. Karavelioglu E, Eser O, Haktanir A. Pneumocephalus and pneumorrhachis after spinal surgery: case report and review of the literature. Neurol Med Chir (Tokyo). 2014;54(5):405-7. doi:10.2176/nmc.cr2013-0118. 
15. Ozturk E, Kantarci M, Karaman K, Basekim CC, Kizilkaya E. Diffuse pneumocephalus associated with infratentorial and supratentorial hemorrhages as a complication of spinal surgery. Acta Radiol. 2006Jun;47(5):497-500. doi: 10.1080/02841850600644766.

16. Schievink WI, Meyer FB, Atkinson JL, Mokri B. Spontaneous spinal cerebrospinal fluid leaks and intracranial hypotension. J Neurosurg.1996 Apr;84(4):598-605. doi: 10.3171/jns.1996.84.4.0598.

17. Daele JJ, Goffart Y, Machiels S. Traumatic, iatrogenic, and spontaneous cerebrospinal fluid (CSF) leak: endoscopic repair. B-ENT.2011;7 Suppl 17:47-60.

18. Horowitz G, Fliss DM, Margalit N, Wasserzug O, Gil Z. Association between cerebrospinal fluid leak and meningitis after skull base surgery. Otolaryngol Head Neck Surg. 2011 Oct;145(4):689-93. doi:10.1177/0194599811411534.

19. Grotenhuis JA. Costs of postoperative cerebrospinal fluid leakage: 1-year, retrospective analysis of 412 consecutive nontrauma cases. Surg Neurol. 2005 Dec;64(6):490-3, discussion 493-4. doi:10.1016/j.surneu.2005.03.041.

20. Giovanni S, Della Pepa GM, La Rocca G, Lofrese G, Albanese A, Maria G, et al. Galea-pericranium dural closure: can we safely avoid sealants? Clin Neurol Neurosurg. 2014 Aug;123:50-4. doi:10.1016/j.clineuro.2014.05.005.

21. Green AL, Arnaud A, Batiller J, Eljamel S, Gauld J, Jones P, et al. A multicentre, prospective, randomized, controlled study to evaluate the use of a fibrin sealant as an adjunct to sutured dural repair. Br J Neurosurg. 2015 Feb;29(1):11-17. doi:10.3109/02688697.2014.948808.

22. Bernal-Sprekelsen M, Alobid I, Mullol J, Trobat F, Tomás-Barberán M. Closure of cerebrospinal fluid leaks prevents ascending bacterial meningitis. Rhinology. 2005 Dec;43(4):277-81.

23. Turgut $M$, Akyüz 0 . Symptomatic tension pneumocephalus: an unusual post-operative complication of posterior spinal surgery. 2007 Jul;14(7):666-8. doi: 10.1016/j.jocn.2006.02.021.

24. Guo X, Zhu Y, Hong Y. Efficacy and Safety of Intraoperative Lumbar Drain in Endoscopic Skull Base Tumor Resection: A Meta-Analysis. Front Oncol. 10:606, 2020.

\section{Supplementary Tables}

Supplementary table I. Comparisons of baseline and post-surgery characteristics between non-p-CFL and p-CFL 


\begin{tabular}{|c|c|c|c|c|}
\hline & $\begin{array}{l}\text { Non } p-C F L \\
(n=221)\end{array}$ & $\begin{array}{l}p-C F L \\
(n=32)\end{array}$ & Test value & $\begin{array}{l}P \\
\text { value }\end{array}$ \\
\hline Age, y, median (IQR) & $51(40-60)$ & $48(35.5-57)$ & $Z=-1.065$ & 0.287 \\
\hline Female, n (\%) & $112(50.7)$ & $14(43.8)$ & $c^{2}=0.537$ & 0.464 \\
\hline Hypertension, n (\%) & $56(25.3)$ & $6(18.8)$ & $c^{2}=0.656$ & 0.418 \\
\hline Diabetes mellitus, n (\%) & $18(8.1)$ & $2(6.3)$ & $c^{2}=0.138$ & 0.710 \\
\hline \multicolumn{5}{|l|}{ Intra-operative characteristics } \\
\hline Trans-single nostril & $166(75.1)$ & $24(75.0)$ & $c^{2}=0.001$ & 0.989 \\
\hline Intra-operative CFL, n (\%) & $18(8.1)$ & $32(100)$ & $c^{2}=148.732$ & $<0.001$ \\
\hline \multicolumn{5}{|l|}{ Intra-operative repair measures } \\
\hline Free fat interositional graft & $22(10.0)$ & $25(78.1)$ & $c^{2}=85.879$ & $<0.001$ \\
\hline Lumbar cistern drainage & $30(13.6)$ & $24(75.0)$ & $c^{2}=62.822$ & $<0.001$ \\
\hline Balloon compression & $1(0.5)$ & $4(12.5)$ & $c^{2}=20.943$ & $<0.001$ \\
\hline Artificial dura mater implantation & $153(69.5)$ & $32(100.0)$ & $c^{2}=13.275$ & $<0.001$ \\
\hline $\begin{array}{l}\text { duration time of operation, min, median } \\
\text { (IQR) }\end{array}$ & $\begin{array}{l}105(80- \\
140)\end{array}$ & $\begin{array}{l}222(175- \\
255)\end{array}$ & $Z=-6.941$ & $<0.001$ \\
\hline Tumor size, mm & $23(18-30)$ & $26(20-34)$ & $Z=-1.676$ & 0.094 \\
\hline Pathology types, n (\%) & & & $c^{2}=38.975$ & $<0.001$ \\
\hline Non-functional tumor & $84(38.0)$ & $4(12.5)$ & & \\
\hline Functional adenoma & $58(26.2)$ & $6(18.8)$ & & \\
\hline Meningioma & $2(0.9)$ & $9(28.1)$ & & \\
\hline Craniopharyngioma & $12(5.4)$ & $10(31.3)$ & & \\
\hline Others, & $65(29.4)$ & $3(9.4)$ & & \\
\hline \multicolumn{5}{|l|}{ Post-operative characteristics } \\
\hline The first-day NP, n (\%) & $27(12.2)$ & $13(40.6)$ & $c^{2}=16.947$ & $<0.001$ \\
\hline NP change, $n(\%)$ & & & $c^{2}=188.637$ & $<0.001$ \\
\hline No NP & 207 (93.7) & $0(0)$ & & \\
\hline Decreased & $10(4.5)$ & $8(25.0)$ & & \\
\hline
\end{tabular}




\begin{tabular}{|lllll|}
\hline Unchanged & $4(1.8)$ & $8(25.0)$ & & \\
\hline Increased & $0(0)$ & $16(50)$ & & \\
\hline High fever, $\mathrm{n}(\%)$ & $26(11.8)$ & $20(62.5)$ & $\mathrm{c}^{2}=48.368$ & $<0.001$ \\
\hline Infection, $\mathrm{n}(\%)$ & $26(11.8)$ & $20(62.5)$ & $\mathrm{c}^{2}=48.090$ & $<0.001$ \\
\hline Residual of tumor, n (\%) & $109(49.3)$ & $12(37.5)$ & $\mathrm{c}^{2}=1.565$ & 0.211 \\
\hline Long-term hypopituitarism, $\mathrm{n}(\%)$ & $92(41.6)$ & $13(40.6)$ & $\mathrm{c}^{2}=0.012$ & 0.914 \\
\hline Duration of hospitalization, days & $5(4-7)$ & $17(11-24)$ & $\mathrm{c}^{2}=-7.883$ & $<0.001$ \\
\hline
\end{tabular}

The others of pathology section included growth hormone (GH) adenomas, prolactin (PRL) adenomas, adrenocorticotropic hormone (ACTH) adenomas, thyroid-stimulating hormone (TSH) adenoma, gonadotroph adenomas and mixed tumor.

NCCT, non-contrast computed tomography; CFL, cerebral-spinal fluid leakage; NP: NCCT pneumocephalus; IQR, inter-quartile range.

Supplementary table II. Multivariate regression analysis for variables associating with p-CFL

\begin{tabular}{|c|c|c|c|c|}
\hline Model 1 & $\mathrm{OR}$ & $95 \% \mathrm{Cl}$ & $P$ value & -2 log likelihood \\
\hline & & & & 113.764 \\
\hline The first-day NP & 6.176 & $2.134-17.871$ & 0.001 & \\
\hline Operative duration time & 1.027 & $1.017-1.036$ & $<0.001$ & \\
\hline Trans-single nostril & 1.388 & $0.459-4.198$ & 0.562 & \\
\hline Pathology types & 1.061 & $0.755-1.491$ & 0.734 & \\
\hline Tumor size & 1.005 & $0.963-1.047$ & 0.833 & \\
\hline \multirow[t]{2}{*}{ Model 2} & OR & $95 \% \mathrm{Cl}$ & $P$ value & -2 log likelihood \\
\hline & & & & 40.231 \\
\hline The first-day NP & 2.521 & $0.438-14.519$ & 0.301 & \\
\hline dynamic change of NP & 21.192 & $6.292-71.373$ & $<0.001$ & \\
\hline Operative duration time & 1.019 & $1.003-1.034$ & 0.018 & \\
\hline Trans-single nostril & 2.356 & $0.302-18.402$ & 0.414 & \\
\hline Pathology types & 1.387 & $0.765-2.515$ & 0.282 & \\
\hline Tumor size & 1.026 & $0.952-1.106$ & 0.497 & \\
\hline
\end{tabular}


NCCT, non-contrast computed tomography; CFL, cerebral-spinal fluid leakage; NP: NCCT pneumocephalus; IQR, inter-quartile range.

\section{Figures}
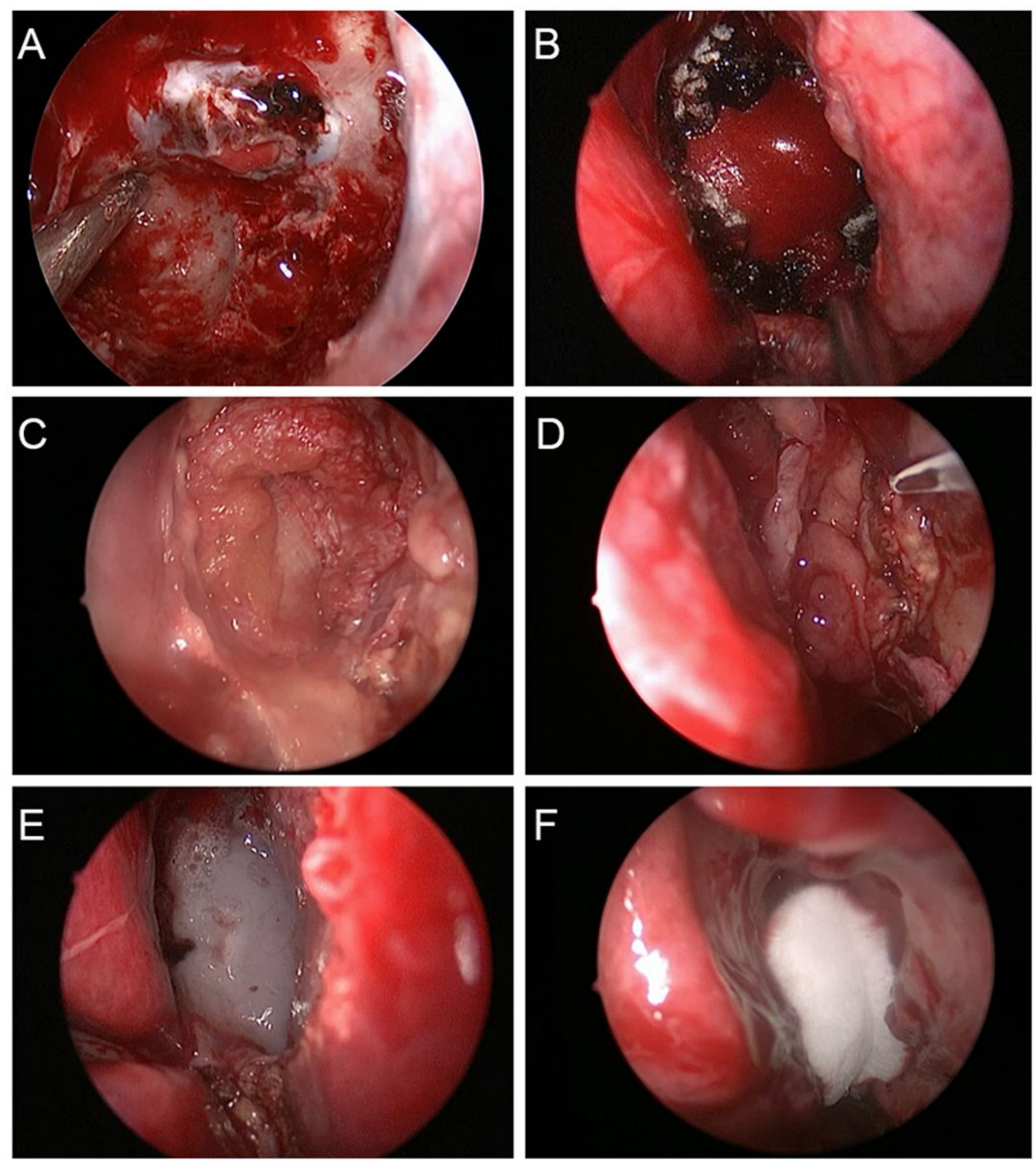

Figure 1 
Multilayered repair procedure for cerebrospinal fluid leakage in endoscopic transsphenoidal surgery. (A) A piece of artificial dura mater was inserted into the subdural space. (B) Another piece of artificial dura mater was place in the epidural space. (C) Autogenous fascia lata was placed on sellar floor for further repair. (D) The pediculate nasoseptal flap was used to reconstruct skull base defect. (E) Fibrin Sealant was used for reinforcement of skull base defect repair. (F) The nasal cavity was filled with Nasopore dressing to strengthen the repair of skull base defect.

\section{A}

The first day after surgery
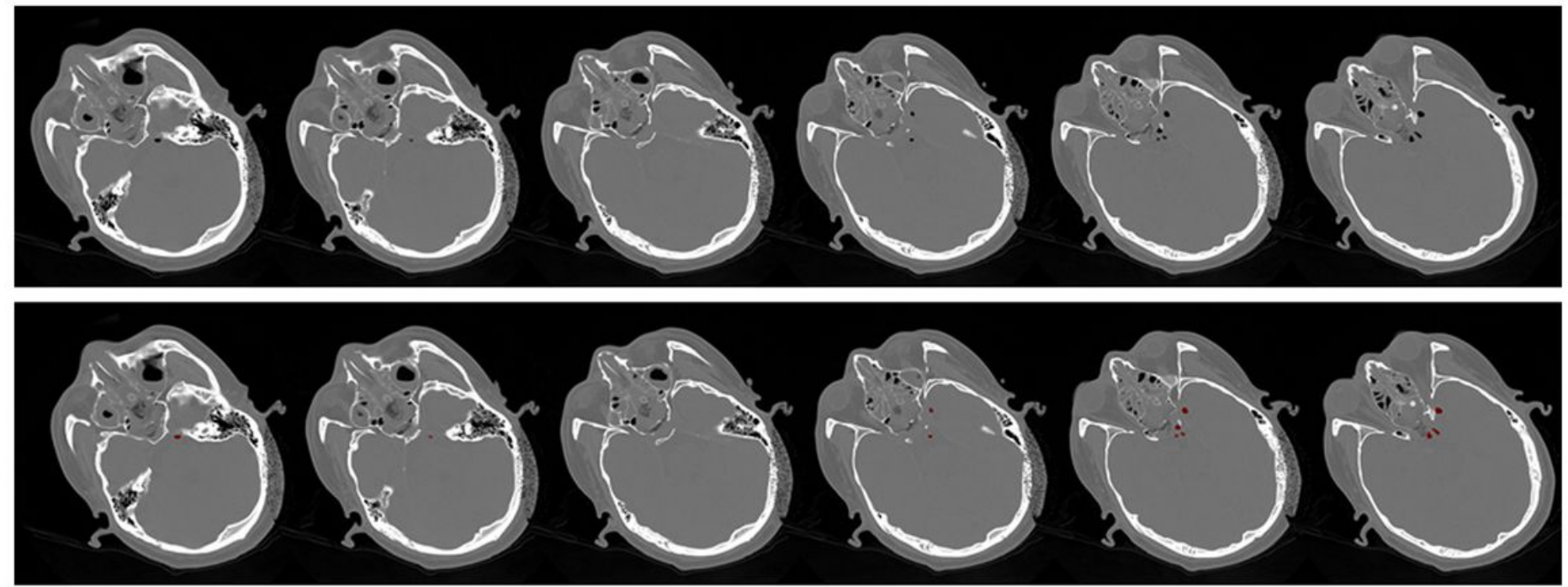

B

The fourth day after surgery
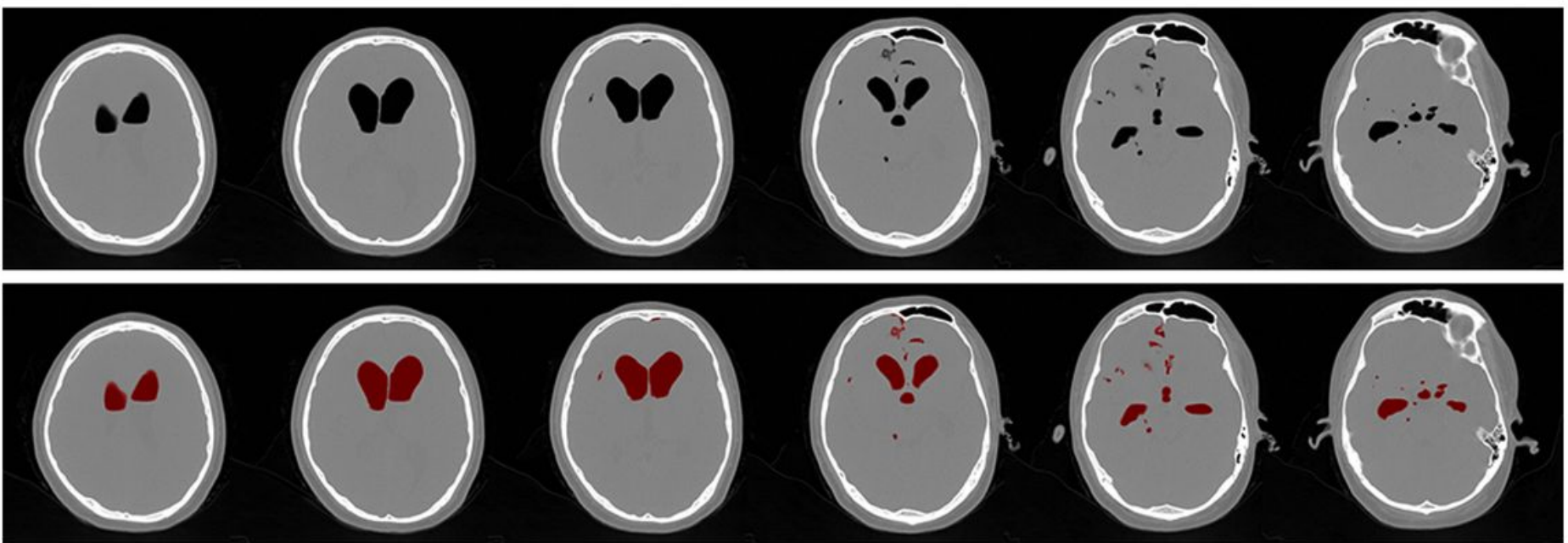

Figure 2

NP volume measurement on the first day and the fourth day after endoscopic transsphenoidal surgery. This is a case of 45-year-old male diagnosed with tuberculum sellae meningioma. A. On the first day after operation, a small amount of CT pneumocephalus was found, which was $2.1 \mathrm{ml}$. B. On the fourth day after operation, CT scan showed increased pneumocephalus volume, which was $23.7 \mathrm{ml}$. Cerebrospinal fluid rhinorrhea was confirmed on the sixth day after operation. The red area represents the pneumocephalus. 


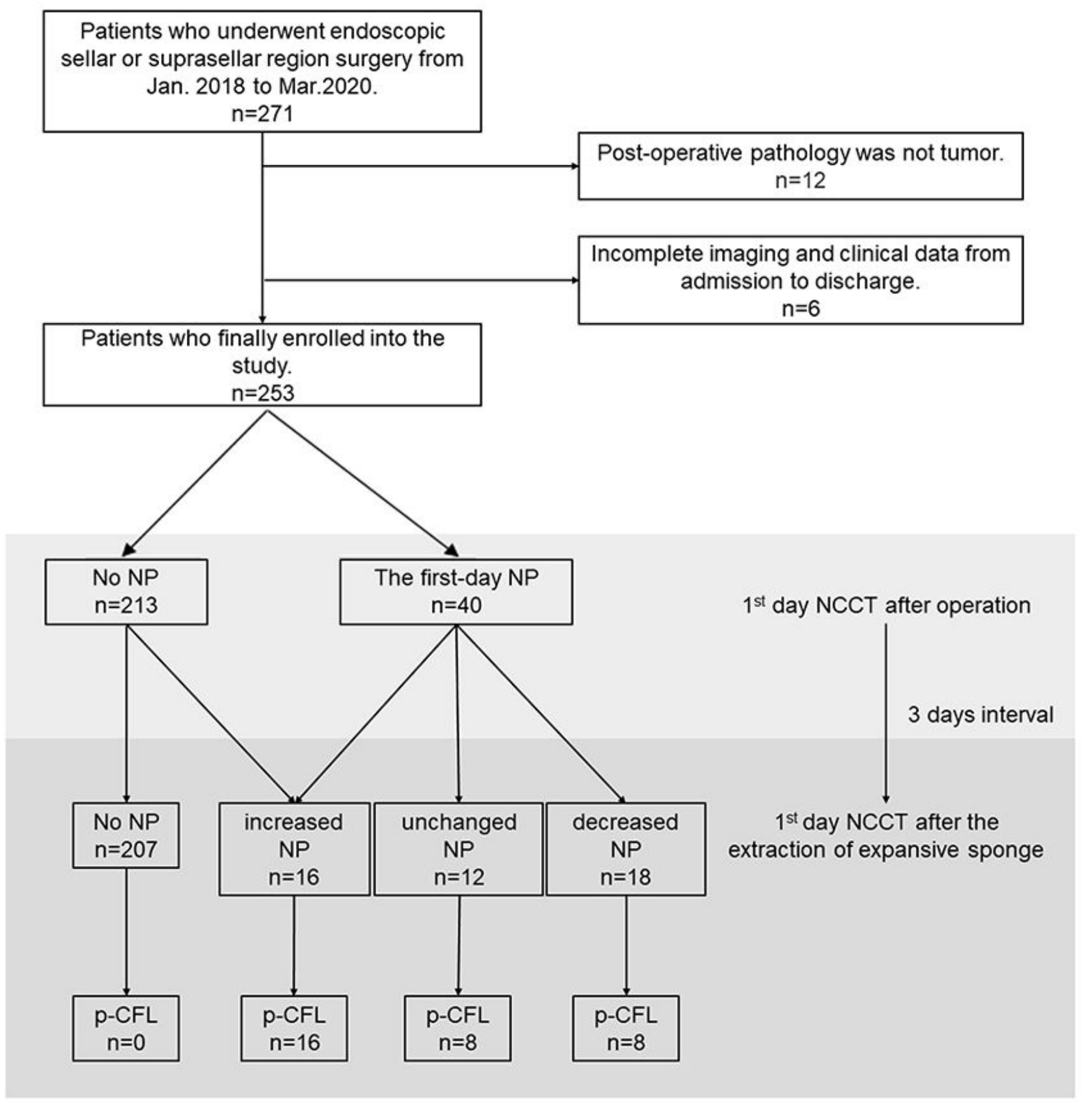

\section{Figure 3}

Flow chart of patient selection, and the whole observation process for the association between NP and $p$ CFL. NCCT: non-contrast computed tomography; NP: NCCT pneumocephalus; p-CFL: post-operational cerebrospinal fluid leakage. 